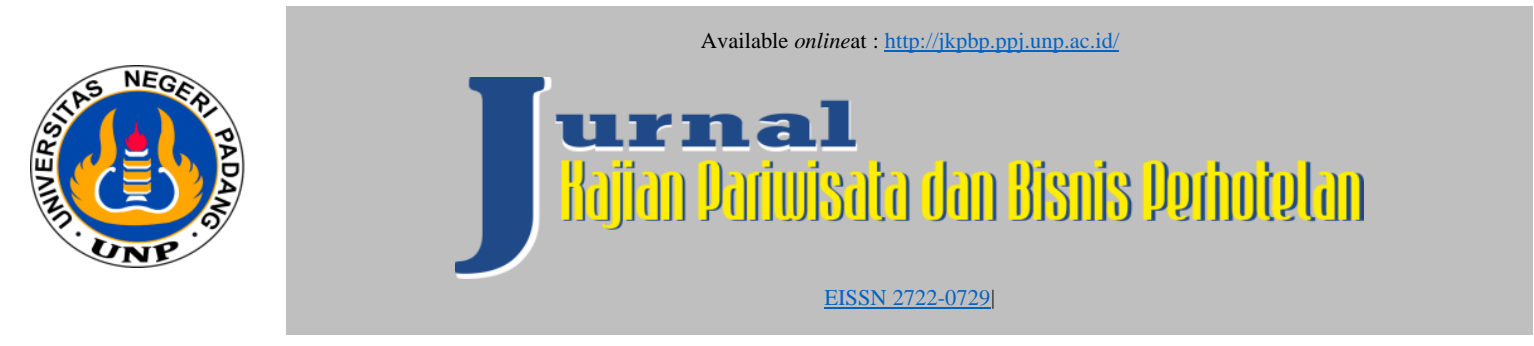

\title{
PENGARUH FASILITAS KERJA KARYAWAN TERHADAP TURNOVER INTENTION DI IMELDA HOTEL WATERPARK-CONVENTION PADANG
}

\author{
Nindi Forendes ${ }^{1}$, Arif Adrian², Adek Kurnia Fiza² \\ ${ }^{1}$ Universitas Negeri Padang \\ ${ }^{2}$ Universitas Negeri Padang \\ ${ }^{2}$ Universitas Negeri Padang
}

Email: forendesnindi11@gmail.com, arifadrian@fpp.unp.ac.id, adek.kurnia@fpp.unp.ac.id,

\begin{abstract}
ABSTRAK
Penelitian ini diawali karena adanya peningkatan tingkat turnover intention di Imelda Hotel Waterpark-Convention. Tujuan dari penelitian ini adalah mengtahui pengaruh fasilitas kerja terhadap turnover intention Di Imelda Hotel Waterpark-Convention Padang. Penelitian ini adalah jenis penelitian Deskriptif Kuantitatif menggunakan Metode assosiatif Kausal yang melibatkan dua variabel yaitu (1) fasilitas kerja,sebagai variabel bebas dengan indikator yaitu Fasilitas Alat Kerja, Fasilitas Kelengkapan Kerja, Fasilitas Sosial, (2) Turnover Intention sebagai variabel terikat, yang terdiri dari indikator pikiran keluar dari pekerjaan, keinginan mencari pekerjaan baru dan keinginan meninggalkan perusahaan. Populasi penelitian adalah semua karyawan di Imelda Hotel Waterpark-Convention padang. Sampel dipenelitian ini memakai teknik nonprobability sampling berjumlah 48 responden. Teknik pengumpulan data dilakukan dengan melalui angket yang menggunakan skala likert yang berjumlah 28 pernyataan yang telah teruji validitas dan realibilitas. Selanjutnya data dideskripsikan serta dilakukan uji persyaratan analisis dan pengujian hipotesis mengunakan Analisis Regresi Linear Sederhana dan koefisien determinasi dengan SPSS versi 16.00.

Hasil Dari Penelitian ini : (1) Fasilitas Kerja ada pada kategori cukup baik (52,1\%), (2) Turnover Intention ada Kategori Baik (58,3\%). Didapati Uji Hipotesis Regresi Linear Sederhana f 4.163 signitifikansi 0,047 < 0,05 Variabel fasilitas kerja, variabel turnover intention signifikansi dengan niali R square 0,083. Fasilitas Kerja mempengaruhi turnover intention 8,3\%, 91,7\% di pengaruhi variabel yang lainnya. Selanjutnya diperoleh nilai t 10,831, signitifikansi $0,000<0,05$, diperoleh hubungan signifikansi. Didapatkan Koefisien regresi $-0,309$, signitifikansi $0,047<0,05$, yang maksudnya meningkat sebesar 1satuan Fasilitas Kerja menurun 0,309 turnover intention. Berdasarkan hasil penelitian menyarankan agar lebih memaksimalkan fasilitas kerja di hotel agar tidak terjadi turnover yang tinggi.
\end{abstract}

Kata Kunci: Fasilitas Kerja, Turnover Intention 


\section{PENDAHULUAN}

Pada saat liburan, Kota Padang adalah salah satu tujuan wisata di Sumatera Barat yang dikunjungi para wisatawan. Kota Padang selain di kenal sebagai Ibukota Provinsi Sumatera Barat, juga dikenal akan keindahan alamnya terutama pantainya, sehingga banyak wisatawan yang berkunjung ke Kota Padang. Sebagai kota wisata, Kota Padang tidak luput dengan adanya hotel, agar wisatawan merasa nyaman datang berkunjung ke Kota Padang.

"Hotel adalah suatu perusahaan yang dikelola oleh pemiliknya dengan menyediakan pelayanan makanan,minuman dan fasilitas kamar untuk tidur kepada orang-orang yang melakukan perjalanan dan mampu membayar dengan jumlah yang wajar sesuai dengan pelayanan yang diterima tanpa adanya perjanjian khusus"[1]. Dengan adanya layanan akomodasi perhotelan, maka wisatawan yang berkunjung akan merasa nyaman datang kesuatu daerah tujuan wisata, juga menjadi pertimbangan bagi wisatawan untuk menghabiskan waktu lebih lama di Kawasan wisata tersebut . dikota Padang banyak didirikan hotel berbintang, salah satu hotel yang berbintang dikota padang adalah Imelda Hotel Waterpark-Convention Padang. Imelda Hotel Waterpark-Convention Padang salah satu hotel resort berbintang empat kota padang. Lokasi hotel ini di Jalan INTAN No. 12 KOMPLEK L.I.K Ulu Gadut Padang, Sumatera Barat. Hotel ini memiliki 108 kamar dengan berbagai tipe kamar seperti Smart Room, Superior Room, Deluxe Room, Executive Room.

Ketika melaksanakan PLI 2 dibulan Juli - Desember 2019 masalah yang ditemukan penulis berkaitan dengan tingkat keluar masuk karyawan (turnover), jika masalah selalu dibiarkan maka akan muncul masalah baru yaitu turnover intention (niat karyawan untuk keluar masuk didalam perusahaan). "Turnover Intention merupakan kecendrungan atau tingkat dimana seorang karyawan memiliki kemungkinan untuk meninggalkan perusahaan baik secara sukarela maupun tidak sukarela yang disebabkan karena kurang menariknya pekerjaan saat ini dan tersedianya tawaran pekerjaan lain"'[2]. Rasio turnover karyawan sebuah perusahaan diluar batas toleransi ketika mencapai angka $10 \%$ atau lebih dalam waktu satu tahun [3]. Berkaitan dengan hal tersebut, peneliti menemukan bahwa presentase turnover karyawan di Imelda Hotel Waterpark-Convention Padang berada diatas 10\%. Angka turnover yang tinggi menunjukan bahwa manajemen kurang baik dalam mengelola karyawan, atau adanya keluhan-keluhan karyawan yang tidak ditanggapi serius oleh manajemen [4].

Permasalahan selanjutnya yang penulis temui adalah karyawan mengganti Uniform kerja dikamar mandi tamu dikarenakan tidak adanya loker, tidak kesesuaian gaji karyawan dengan jabatan yang ditempati maka karyawan tidak puas dalam bekerja, dan kurangnya motivasi dari pimpinan terhadap karyawan yang pekerjaannya bagus tetapi tidak pernah diberikan reward/penghargaan.

Kemudian juga terdapat keluhan dari karyawan yang merasa bahwa dia sudah lama bekerja namun susah atau butuh waktu yang lama untuk mendapatkan kenaikan jabatan atau promosi jabatan dari hotel. Karyawan wanita yang shift sore tidak ada dari pihak hotel (driver) untuk mengantarkan karyawan pulang karena jadwal kerja driver 09.00-18.00. Tidak adanya telephone office engineering dan security sehingga mengakibatkan terhalangnya komunikasi antar karyawan. Office engineering sangat sempit dan bangunannya pun sudah tidak bagus lagi, selain itu bangunan office engineering dan housekeeping terpisah dari bangunan hotel sehingga tidak sampai sambungan koneksi wifi ke office housekeeping dan engineering.

\section{METODOLOGI PENELITIAN}

Penelitian ini tergolong kepada penelitian kuantitatif dengan pendekatan asosiatif Kausal, populasi pada penelitian yang dilakukan yakni semua Karyawan Di Imelda Hotel Waterpark-Convention Padang. Sampel yang diambil dengan metode sampel jenuh dimana semua anggota populasi dijadikan sampel penelitian [5]. Data dikumpulkan dengan menyebarkan angket yang berisikan pernyataan-pernyataan dengan 5 pilihan jawaban, yang sudah disusun kemudian diberikan kepada semua responden yang telah diuji validasinya serta reliabilitasnya terlebih dahulu. Dengan pengujian hipotesis menggunakan 
Analisis regresi linear sederhana, dan melihat kontribusi pengaruh antara variabel $\mathrm{X}$ terhadap variabel Y menggunakan koefisien determinan.

\section{HASIL PENELITIAN DAN PEMBAHASAN}

\section{Hasil Penelitian}

Hasil Uji variabel Fasilitas Kerja disusun dengan pernyatan dan beberapa pernyataan yang sudah di uji Validitas serta Reliabilitasnya. Kemudian Kuesioner diberikan ke 48 orang diberikan jawaban.

Tabel 1.Klasifikasi skor jawaban responden mengenai variabel fasilitas kerja

\begin{tabular}{|l|l|l|l|}
\hline Kategori & Rentang Skor & F & Persentase (\%) \\
\hline Sangat Baik & $\geq 51,9$ & 1 & 2,1 \\
\hline Baik & $43,3-<51,9$ & 21 & 43,7 \\
\hline Cukup & $\mathbf{3 4 , 7 - < 4 3 , 3}$ & $\mathbf{2 5}$ & $\mathbf{5 2 , 1}$ \\
\hline Buruk & $26,1-<34,7$ & 1 & 2,1 \\
\hline Sangat Buruk & $<26,1$ & 0 & 0 \\
\hline Total & $\mathbf{4 8}$ & $\mathbf{1 0 0}$ \\
\hline
\end{tabular}

Sumber:Hasil Olahan (2020)

Sesuai dengan kategori skor dalam hasil penelitian, bahwasannya penilaian mengenai Fasilitas Kerja sebesar 52,1\% ada pada rentang skor 34,7 - 43,3 dengan klasifikasi cukup baik. Jadi disimpulkan bahwasannya penilaian tentang Fasilitas Kerja di Imelda Hotel Waterpark-Convention Padang adalah cukup baik.

Sedangkan data variabel turnover intention dari 28 butir pernyataan yang sudah diuji validitas serta reliabilitasnya. Kemudian kuesioner disebarkan ke 48 responden untuk di jawab.

Tabel 2.Klasifikasi Skor Jawaban Responden Tentang Turnover Intention

\begin{tabular}{|l|l|l|l|}
\hline Kategori & Rentang Skor & F & $\begin{array}{l}\text { Persentase } \\
(\mathbf{\%})\end{array}$ \\
\hline Sangat Baik & $\geq 60$ & 19 & 39,6 \\
\hline Baik & $\mathbf{5 0}-<\mathbf{6 0}$ & $\mathbf{2 8}$ & $\mathbf{5 8 , 3}$ \\
\hline Cukup & $40-<50$ & 1 & 2,1 \\
\hline Buruk & $30-<40$ & 0 & 0 \\
\hline Sangat Buruk & $<30$ & 0 & 0 \\
\hline Total & & $\mathbf{4 8}$ & $\mathbf{1 0 0}$ \\
\hline
\end{tabular}

Sumber: Hasil Olahan (2020)

Sesuai dengan kategori skor dan nilai rata-rata di hasil penelitian, bahwasannya penilaian mengenai turnover intention sebesar 58,3\% berada pada rentang skor 50 - <60 dengan kategori baik. Jadi disimpulkan bahwasannya penilaian mengenai Turnover Intention di Imelda Hotel WaterparkConvention Padang adalah baik.

Kemudian dilakukan uji persyaratan analisis dan didapatkan hasil yaitu nilai Asym Sig yaitunya 0,224 untuk variabel fasilitas kerja dan 0,440 untuk turnover intention di Imelda Hotel WaterparkConvention Padang, dengan nilai > dari 0,05, Jadi bisa disebutkan bahwasannya Variabel Terdistribusi Normal. Lalu untuk Uji homogen didapatkan nilai signitifikansi yaitu 0,642 nilai 
signifikannya $>0,05$, yang maksudnya Sig dari nilai signifikansi. Jadi di simpulkan bahwasannya data Populasi data bersifat Homogen. Sedangkan Uji linear didapatkan nilai signifikan 0,106 yang mana lebih besar dari pada 0,05, maksudnya ada hubungan yang linear secara signifikan antar variabel fasilitas kerja dan turnover intention. Kemudian utuk hipotesis diperoleh nilai $\mathrm{F} 4,163$ dengan sig. 0,047 kecil dari 0,05 dan didapatkan nilai t 10,831 dengan taraf signitifikansi 0,000< 0,05 maksudnya Variabel x mengartikanVariabel y signifikansi. Maka Variabel fasilitas kerja mempengaruhi variabel turnover intention, Jadi Ha di terima sedangkan Ho di tolak. Sedangkan Koefisien Regresi didapatkan - 0,309 dengan tingkat signifikansi 0,047 < 0,05, maknanya meningkatkan setiap 1satuan fasilitas kerja dapat menurunkan 0.309 turnover intention. $\mathrm{R}$ square $=$ 0,083 maknanya kontribusi variabel fasilitas kerja terhadap turnover intention adalah 8,3\%, sedangkan $91,7 \%$ ditentukan oleh variabel lain.

\section{Pembahasan}

\section{a. Fasilitas Kerja}

Sesuai hasil penilaian terhadap 48 orang sampel, data variabel Fassilitas Kerja di Imelda Hotel Waterpark-Convention Padang dapat dikategorikan cukup dengan presentase 52,1\%. "Fasilitas kerja adalah sebagai sarana yang diberikan perusahaan untuk mendukung jalannya nada perusahaan dalam mencapai tujuan yang ditetapkan oleh pemegang kendali”[6]. Dari hasil penelitian karyawan Imelda Hotel Waterpark-Convention berpendapat bahwa fasilitas kerja yang mereka terima belumlah memadai dalam menunjang perkerjaan mereka, untuk itu dibutuhkan Tindakan dari pihak manajemen untuk meningkatkan fasilitas kerja karyawan. Ketersediaan fasilitas kerja yang memadai bukan hanya dapat menekan turnover, tetapi juga dapat memaksimalkan kinerja karyawan [7], karyawan dapat bekerja dengan efektif dan efisien dalam memberikan pelayan dengan fasilitas yang memadai tersebut [8].

\section{b. Turnover Intention}

Sesuai hasil penilaian terhadap 48 orang sampel, data variabel turnover intention di Imelda Hotel Waterpark-Convention Padang sebanyak 58,3\% responden termasuk kategori baik. Artinya turnover intention di Imelda Hotel Waterpark-Convention Padang menyatakan baik. "Turnover Intention adalah hasil evaluasi individu mengenai kelanjutan hubungan dengan perusahaan dimana dia bekerja namun belum diwujudkan dalam tindakan nyata" [9].

Hasil penelitian menunjukan bahwa Sebagian besar karyawan memiliki keinginan atau minat untuk meninggalkan organisasi, ini mesti menjadi perhatian oleh manajemen Imelda Hotel WaterparkConvention. Tingginya tingkat turnover karyawan tentunya akan mengganggu operasional perusahaan [10].

\section{c. Pengaruh Fasilitas Kerja Terhadap Turnover Intention di Imelda Hotel Waterpark-Convention Padang}

Didapat dari persamaan diperoleh koefisien regresi - 0.309 signtifikansi $0,047<0,05$, maknanya kanaikan sebesar 1satuan fasiilitas Kerja menurunkan 0,309 satuan turnover intention, $\mathrm{R}$ square 0,083 maknanya dari Variabel pengaruh Fasilitas Kerja Terhadap turnover intention di Imelda Hotel Waterpark-Convention kota Padang adalah 8,3\%, sedangkan 91,7\% ditentukan oleh variabel yang lain. Dari hasil di atas dapat dilihat bahwasanya peningkatan fasilitas kerja karyawan dapat menurunkan minat karyawan untuk meninggalkan organisasi, meski berkontribusi hanya sebesar 8,3\% ini tetaplah harus menjadi perhatian pihak manajemen. Kontribusi faktor lain seperti stress kerja dan kepuasan kerja juga harus menjadi perhatian manajemen dalam menekan tingkat turnover karyawan [11]. Rendah nya tingkat turnover karyawan akan menciptakan suasana kerja yang kondusif dan dapat mengoptimalkan kinerja karyawan dalam memberikan pelayanan pada tamu di Imelda Hotel Waterpark-Convention. 


\section{KESIMPULAN}

Fasiilitas kerja di Imelda Hotel Waterpark-Convention Padang menunjukan bahwa (1) keseluruh Fasilitas Kerja di Imelda Hotel Waterpark-Convention Padang Kategori Cukup yang persentasenya sebesar 52,1\% . Jadi dapat disimpulkan karyawan menilai fasilitas kerja di Imelda Hotel WaterparkConvention Padang secara keseluruhan cukup baik. (2) Secara keseluruhan turnover intention di Imelda Hotel Waterpark-Convention Padang tergolong pada kategori baik dengan nilai persentase 58,3\%. Jadi dapat disimpulkan bahwa turnover intention di Imelda Hotel Waterpark-Convention padang Kategori Baik. (3) terdapat Pengaruh signifikansi fasilitas Kerja Terhadap turnover intention Di Imelda Hotel Waterpark-Convention Padang, dengan kontribusi pengaruh 8,3\%, serta 91,7\% di pengaruhi variabel yang lainnya. (4) Variabel fasilitas kerja (X) Pengaruh negative signifikan Terhadap Variabel Turnover Intention (Y), yang berarti semakin tinggi fasilitas kerja yang diberikan pada karyawan maka semakin turun pula tingkat turnover intention karyawan di Imelda Hotel Waterpark-Convention.

\section{DAFTAR PUSTAKA}

[1] Sulastiyono. 2011. Manajemen Penyelanggaraan Hotel. Bandung: Alfabeta

[2] Robbins. 2014. Perilaku Organisasi,Edisi 16. Jakarta : Salemba Empat

[3] Kasmir. 2016. Analisis Laporan Keuangan. Jakarta : Raja Grafindo Persada.

[4] I. Meirina, F. Ferdian, P. Pasaribu, and H. Suyuthie, "the Influence of Work Environment Towards Turnover Intention of Employee of 4 Star Hotels in Padang City," J. Bus. Hosp. Tour., vol. 4, no. 2, pp. 1-8, 2018, doi: 10.22334/jbhost.v4i2.120.

[5] Sugiyono. 2015. Metode Penelitian Kuantitatif, Kualitatif dan R\&D. Bandung: Alfabeta.

[6] Bary. 2012. Human Resources Management. Jakarta : Elex Media Komputindo.

[7] K. Anam, and E. Rahardja, "PENGARUH FASILITAS KERJA, LINGKUNGAN KERJA NON FISIK DAN KEPUASAN KERJA TERHADAP KINERJA KARYAWAN (Studi pada Pegawai Dinas Perindustrian dan Perdagangan Provinsi Jawa Tengah)," Diponegoro Journal of Management, vol. 6, no. 4, pp. 502-512, Aug. 2017.

[8] LISTYANI, Indah. Pengaruh Fasilitas Kerja dan Komunikasi Kerja Terhadap Kinerja Karyawan. JMK (Jurnal Manajemen dan Kewirausahaan), [S.1.], v. 1, n. 1, p. 56-64, jan. 2016. ISSN 26560771

[9] Mobley,W.H. 2011. Pergantian Karyawan : Sebab, Akibat dan Pengendaliannya. Alih Bahasa : Nurul Imam. Jakarta : PT Pustaka Binaman Pressindo.

[10] Waspodo, A. A., Handayani, N. C., \& Paramita, W. (2017). PENGARUH KEPUASAN KERJA DAN STRES KERJA TERHADAP TURNOVER INTENTION PADA KARYAWAN PT. UNITEX DI BOGOR. JRMSI - Jurnal Riset Manajemen Sains Indonesia, 4(1), 97-115. Retrieved from http://journal.unj.ac.id/unj/index.php/jrmsi/article/view/780

[11] PARTA YUDA, Ida Bagus Dwihana; ARDANA, I Komang. PENGARUH KEPUASAN KERJA DAN STRES KERJA TERHADAP TURNOVER INTENTION PADA KARYAWAN HOTEL HOLIDAY INN EXPRESS. E-Jurnal Manajemen, [S.1.], v. 6, n. 10, p. 5319 - 5347, oct. 2017. ISSN 2302-8912. 